\title{
Effect of Surface Geology on Ground Motions: The Case of Station TAP056 - Chutzuhu Site
}

\author{
Kuo-Liang Wen ${ }^{1,2, *}$, Che-Min Lin ${ }^{1}$, Hsien-Jen Chiang ${ }^{1}$, Chun-Hsiang Kuo ${ }^{1}$, \\ Yu-Chih Huang ${ }^{1}$, and Hsin-Chieh $\mathrm{Pu}^{1}$ \\ ${ }^{1}$ Institute of Geophysics, National Central University, Chung-Li 320, Taiwan, ROC \\ ${ }^{2}$ National Center for Research on Earthquake Engineering, Taipei, Taiwan, ROC
}

Received 26 December 2006, accepted 8 October 2007

\begin{abstract}
In the Tatun mountain area of northern Taiwan are two strong motion stations approximately $2.5 \mathrm{~km}$ apart, TAP056 and TAP066 of the TSMIP network. The accelerometer at station TAP056 is often triggered by earthquakes, but that at TAP066 station is not. Comparisons of vertical and horizontal peak ground accelerations reveal PGA in the vertical, east-west, and north-south components at TAP056 station to be 3.89, 7.57, and 5.45 times those at station TAP066, respectively. The PGA ratio does not seem to be related to earthquake source or path. Fourier spectra of earthquake records at station TAP056 always have approximately the same dominant frequency; however, those at station TAP066 are different due to different sources and paths of different events. This shows that spectra at TAP056 station are mainly controlled by local site effects. The spectral ratios of TAP056/TAP066 show the S-wave is amplified at around $8 \sim 10 \mathrm{~Hz}$. The horizontal/vertical spectral ratios of station TAP056 also show a dominant frequency at about 6 and $8 \sim 10 \mathrm{~Hz}$. After dense microtremor surveying and the addition of one accelerometer just 20 meters away from the original observation station, we can confirm that the top soft soil layer upon which the observation station is constructed generates the local site response at station TAP056.
\end{abstract}

Key words: Peak ground acceleration, Local site effect, Spectral ratio, Microtremor survey

Citation: Wen, K. L., C. M. Lin, H. J. Chiang, C. H. Kuo, Y. C. Huang, and H. C. Pu, 2008: Effect of surface geology on ground motions: The case of station TAP056-Chutzuhu site. Terr. Atmos. Ocean. Sci., 19, 451-462, doi: 10.3319/TAO.2008.19.5.451(T)

\section{INTRODUCTION}

The Taiwan Strong Motion Instrumentation Program (TSMIP) operated by the Central Weather Bureau (Shin 1993; Kuo et al. 1995) has about 100 free-field strong motion accelerometers installed in the Taipei metropolitan area. Two adjacent stations, TAP056 and TAP066, are located in the Tatun mountain area. These stations are separated by approximately $2.5 \mathrm{~km}$ horizontally, and 356 meters in elevation. TAP066 station originally housed an A800 strong motion accelerometer. For admission into the TSMIP network, an IDS3602 accelerometer was installed on 30 September 1992. In 8 September 1993 an A900 accelerometer was installed and the IDS3602 accelerometer was removed on 8 August 1994. Since that time, the operation of the station has been normal. Station TAP056 had an A900 accelerometer installed on 15 December 1994 as this accelerometer was

* Corresponding author

E-mail:wenkl@earth.ncu.edu.tw triggered so often that the memory would fill before large events occurred. For example, the 25 June 1996 earthquake was recorded at TAP066 station but not at TAP056. Consequently, an ETNA strong motion instrument was installed because of its increased memory capacity to accommodate the amount of activity measured at TAP056. When both accelerometers are triggered by earthquakes, peak ground accelerations show marked differences between the two sites. This causes problems in intensity measurement, and can trigger emergency false alarms for the occurrence of damaging earthquakes.

Typically, ground motion recorded by seismometers after an earthquake is affected by source, path, and site effects (Chin and Aki 1991; Beresnev et al. 1994; Chen 2003). Sometimes, construction problems in the recording room may also affect ground motion records (Wen et al. 2001). In this study, earthquakes recorded by these two stations are selected. Ground motions are analyzed in terms of frequency 
and time domain to determine the reasons for this apparent difference between two stations that are so close to one another. Finally, some in situ investigations are performed to prove our finding in this study.

\section{SITE GEOLOGY AND EARTHQUAKE DATA}

Both TAP056 and TAP066 are located in the Tatun mountain area. The geological conditions in this area chiefly consist of andesite lava flows and andesitic pyroclastics.
These volcanic rocks stand on a Pliocene and Miocene basement. Recent alluvium is distributed on riversides, a riverbed, and the lower land near the river mouth. Thickness of the alluvium differs by location. TAP056 is located on the valley slope between the Chishin and Sarmau mountains at the Chutzuhu meteorological observation station of the Central Weather Bureau. TAP066 station is located in the Anpu meteorological observation station, which is on the northern side of Tatun Mountain. Figure 1 shows site conditions and the velocity profile at TAP056, measured from nearby bore- (b)

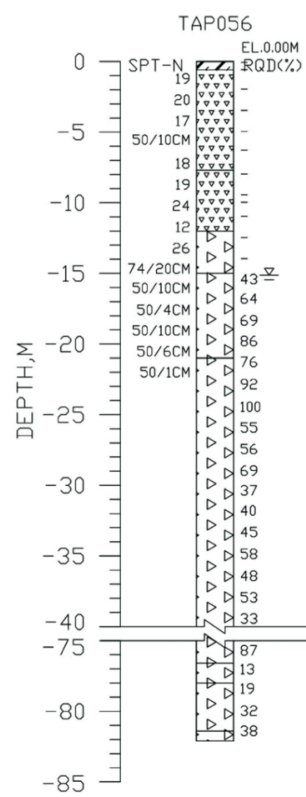

(a)

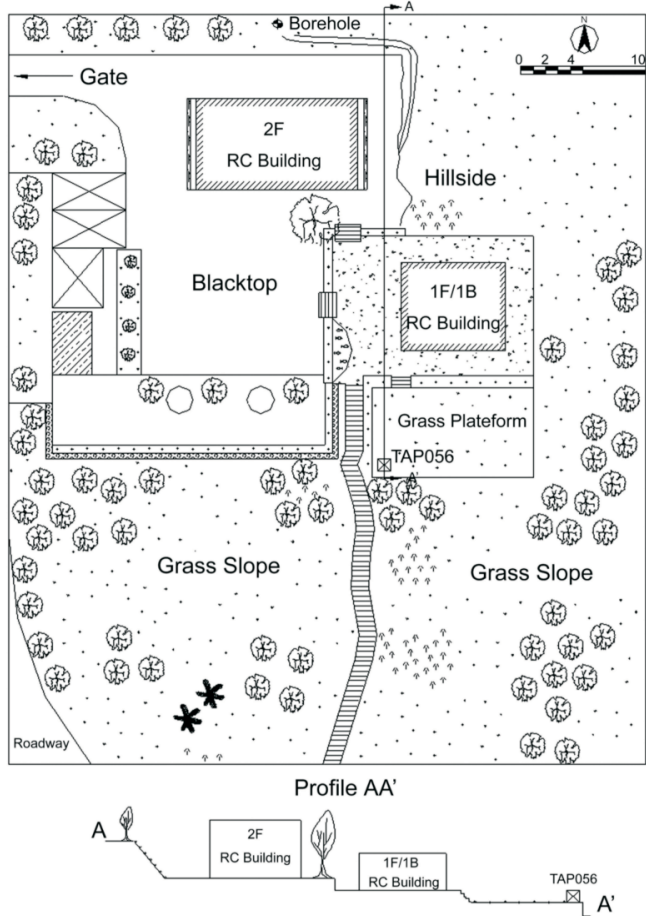

TAP056
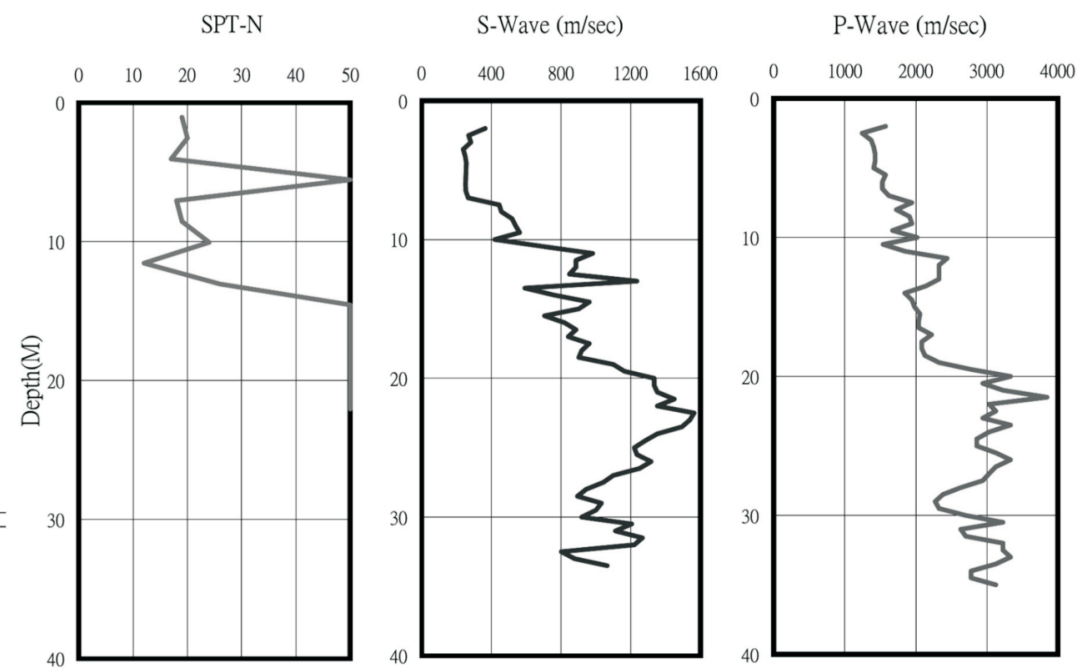

Fig. 1. (a) Locations of Station TAP056 and the nearby drilling hole. (b) Velocity profile which is measured from the borehole near Station TAP056 using the PS-logger method (http://www.cwb.gov.tw). 
hole data. It shows that there is about a $12-\mathrm{m}$ soft weathering layer at the surface with shear wave velocity of about 250 560 msec-1; underlying this is andesite rock with shear wave velocity between $800 \sim 1600 \mathrm{~m} \mathrm{sec}^{-1}$.

After checking the data recorded at these two stations. Station TAP056 has clearly collectedmore data than TAP066. Only 18 earthquakes triggered these two stations at the same time from 1995 to 2002 . The source parameters are listed in Table 1. The magnitudes ranged between 2.4 and 6.9, and the epicenters are shown in Fig. 2. Figure 3 shows an example of the waveforms recorded at these two stations of event no. 1. The epicenter is located in the Tatun mountain area, magnitude is 2.4 , and the duration is not long. The waveforms seem very normal. The peak ground acceleration (PGA) shows a large difference between stations TAP056 and TAP066, and these PGAs do not seem to be generated from spikes.

\section{TIME DOMAIN ANALYSIS}

Peak ground accelerations are listed in Table 2 for the 18 earthquakes recorded simultaneously at both TAP056 and TAP066 from 1995 to 2002. Table 2 shows that the PGA values at TAP056 and TAP066 are very different for the same event, both in vertical and horizontal components. The PGA

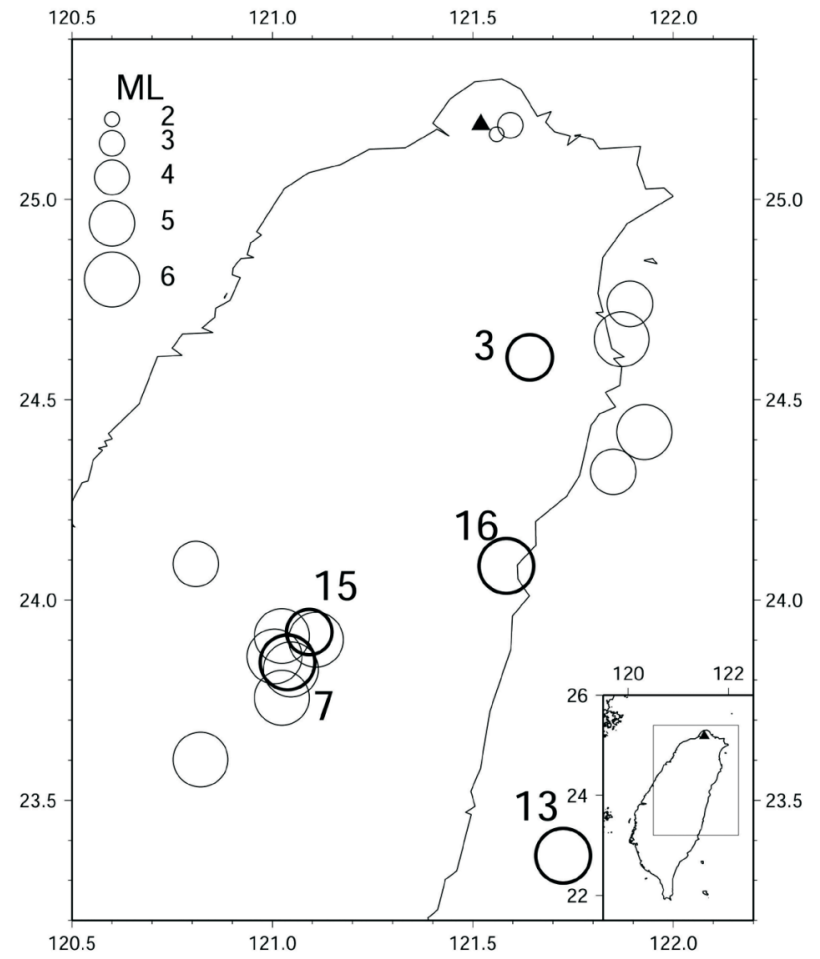

Fig. 2. Epicenter locations for the earthquakes listed in Table 1. The black triangle shows the location of the station. Bold circle symbols show the 5 events that plot the Fourier spectra in Fig. 5. The size of the circle shows the magnitude.

Table 1. Earthquakes recorded by both TAP056 and TAP066 stations.

\begin{tabular}{cccccccr}
\hline \multirow{2}{*}{ Event No. } & \multirow{2}{*}{ Origin Time } & \multicolumn{2}{c}{ Location } & \multirow{2}{*}{ Depth $(\mathbf{k m})$} & \multirow{2}{*}{$\mathbf{M}_{\mathbf{L}}$} & $\begin{array}{c}\text { Azimuth }\left({ }^{\circ}\right) \text { to } \\
\text { TAP066 }\end{array}$ & $\begin{array}{c}\Delta \text { (km) to } \\
\text { TAP066 }\end{array}$ \\
\cline { 3 - 4 }${ }^{\mathbf{0}} \mathbf{N}$ & ${ }^{\circ} \mathbf{E}$ & & & & \\
& $1995 / 07 / 10 / 13: 18$ & 25.16 & 121.56 & 0.39 & 2.4 & 91.26 & 4.82 \\
2 & $1995 / 07 / 14 / 16: 52$ & 24.32 & 121.85 & 8.78 & 5.8 & 122.90 & 101.61 \\
3 & $1995 / 12 / 01 / 03: 17$ & 24.61 & 121.64 & 45.07 & 5.7 & 142.78 & 65.48 \\
4 & $1998 / 05 / 10 / 21: 19$ & 25.19 & 121.59 & 6.28 & 3.1 & 149.01 & 7.45 \\
5 & $1999 / 05 / 07 / 01: 03$ & 24.74 & 121.89 & 4.17 & 5.4 & 154.04 & 62.21 \\
6 & $1999 / 09 / 20 / 17: 57$ & 23.91 & 121.02 & 2.23 & 6.5 & 160.70 & 150.09 \\
7 & $1999 / 09 / 20 / 18: 16$ & 23.84 & 121.04 & 1.10 & 6.7 & 169.08 & 156.49 \\
8 & $1999 / 09 / 20 / 18: 25$ & 24.09 & 120.81 & 14.91 & 5.2 & 174.06 & 141.17 \\
9 & $1999 / 09 / 20 / 21: 46$ & 23.60 & 120.82 & 0.32 & 6.6 & 177.00 & 189.34 \\
10 & $1999 / 09 / 22 / 00: 14$ & 23.83 & 121.05 & 15.59 & 6.8 & 196.39 & 158.11 \\
11 & $1999 / 09 / 22 / 00: 49$ & 23.76 & 121.02 & 8.95 & 6.3 & 197.27 & 166.28 \\
12 & $1999 / 09 / 25 / 23: 52$ & 23.86 & 121.01 & 9.89 & 6.8 & 197.69 & 155.97 \\
13 & $1999 / 11 / 01 / 17: 53$ & 23.36 & 121.73 & 31.33 & 6.9 & 197.77 & 203.18 \\
14 & $2000 / 06 / 10 / 18: 23$ & 23.90 & 121.11 & 16.21 & 6.7 & 198.27 & 148.35 \\
15 & $2000 / 06 / 19 / 21: 56$ & 23.92 & 121.09 & 27.02 & 5.2 & 199.63 & 146.80 \\
16 & $2000 / 09 / 10 / 08: 54$ & 24.09 & 121.58 & 17.74 & 6.2 & 199.66 & 122.14 \\
17 & $2001 / 06 / 14 / 02: 35$ & 24.42 & 121.93 & 17.29 & 6.3 & 202.14 & 94.51 \\
18 & $2002 / 05 / 15 / 03: 46$ & 24.65 & 121.87 & 8.52 & 6.2 & 210.79 & 69.14 \\
\hline
\end{tabular}



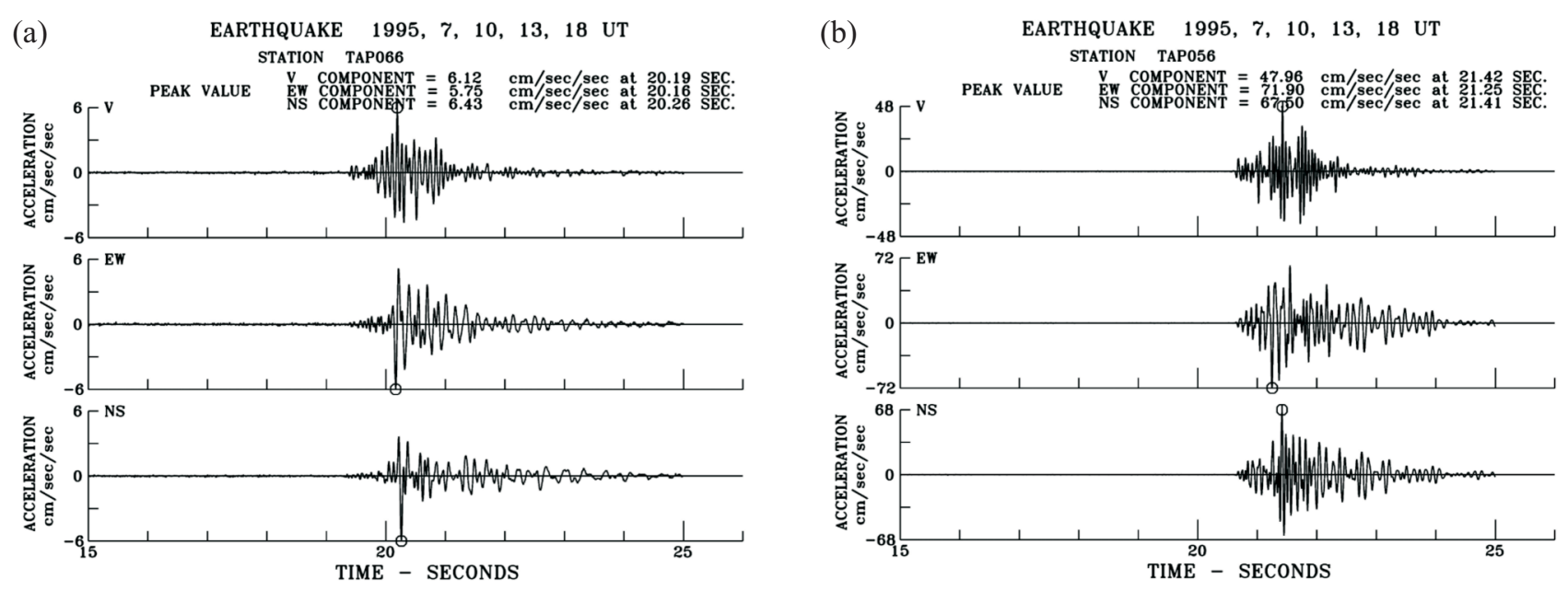

Fig. 3. Accelerograms recorded at TAP056 and TAP066 stations for the 10 July 1995 earthquake.

ratios between these two stations are also shown in Table 2 .

The average PGAratios are 3.89, 7.57, and 5.45, respec tively, for vertical, east-west, and north-south components. The maximum horizontal PGA ratio in the EW component reaches 27.66 for event no. 3 . The preliminary explanation for this difference lies probably in topographic or local site effects. Source and path effects for most events ought to be the same due to the station interval for TAP056 and TAP066, which is negligible when compared to the focal distance as shown in Fig. 1. Figure 4 shows the horizontal PGA contour

Table 2. PGA and PGA ratios of stations TAP056 and TAP066.

\begin{tabular}{|c|c|c|c|c|c|c|c|c|c|}
\hline \multirow{2}{*}{ NO. } & \multicolumn{3}{|c|}{ TAP056 } & \multicolumn{3}{|c|}{ TAP066 } & \multicolumn{3}{|c|}{ TAP056/TAP066 } \\
\hline & EW & NS & $\mathbf{V}$ & $\mathbf{E W}$ & NS & $\mathbf{V}$ & $\mathbf{E W}$ & NS & $\mathbf{V}$ \\
\hline 1 & 71.88 & 67.49 & 47.91 & 5.75 & 6.43 & 6.12 & 12.50 & 10.49 & 7.83 \\
\hline 2 & 31.84 & 25.59 & 5.50 & 2.99 & 3.93 & 1.25 & 10.64 & 6.52 & 4.41 \\
\hline 3 & 84.48 & 69.25 & 16.11 & 3.05 & 3.61 & 1.19 & 27.66 & 19.20 & 13.59 \\
\hline 4 & 48.83 & 34.04 & 20.67 & 8.91 & 7.17 & 6.75 & 5.48 & 4.75 & 3.06 \\
\hline 5 & 16.54 & 15.37 & 7.57 & 3.18 & 3.27 & 1.58 & 5.20 & 4.70 & 4.80 \\
\hline 6 & 10.56 & 10.73 & 4.20 & 4.98 & 6.34 & 1.86 & 2.12 & 1.69 & 2.27 \\
\hline 7 & 14.07 & 13.30 & 4.50 & 6.26 & 6.00 & 3.04 & 2.25 & 2.22 & 1.48 \\
\hline 8 & 386.07 & 201.21 & 125.05 & 26.64 & 15.69 & 24.16 & 14.49 & 12.82 & 5.18 \\
\hline 9 & 7.95 & 7.45 & 2.30 & 2.18 & 3.72 & 1.03 & 3.65 & 2.00 & 2.22 \\
\hline 10 & 24.20 & 22.78 & 6.56 & 5.89 & 7.04 & 2.63 & 4.11 & 3.24 & 2.49 \\
\hline 11 & 14.64 & 13.31 & 3.11 & 3.38 & 3.68 & 1.25 & 4.33 & 3.61 & 2.48 \\
\hline 12 & 10.98 & 9.75 & 3.47 & 3.80 & 5.18 & 1.80 & 2.89 & 1.88 & 1.93 \\
\hline 13 & 30.71 & 19.19 & 6.52 & 5.25 & 5.31 & 1.96 & 5.85 & 3.62 & 3.32 \\
\hline 14 & 40.85 & 24.57 & 7.66 & 5.69 & 6.91 & 2.46 & 7.17 & 3.55 & 3.12 \\
\hline 15 & 12.31 & 13.68 & 2.96 & 2.44 & 2.76 & 0.92 & 5.04 & 4.96 & 3.21 \\
\hline 16 & 20.50 & 23.69 & 6.80 & 8.49 & 9.84 & 3.66 & 2.42 & 2.41 & 1.86 \\
\hline 17 & 53.96 & 42.89 & 14.10 & 5.31 & 8.73 & 5.04 & 10.16 & 4.91 & 2.80 \\
\hline 18 & 53.72 & 35.70 & 16.46 & 5.22 & 6.51 & 4.17 & 10.29 & 5.48 & 3.95 \\
\hline & & & & & & ge $\mathrm{Ra}$ & $7.57 \pm 6.2$ & $5.45 \pm 4.51$ & $3.89 \pm 2$ \\
\hline
\end{tabular}

\footnotetext{
* The unit of PGA is gal.
} 


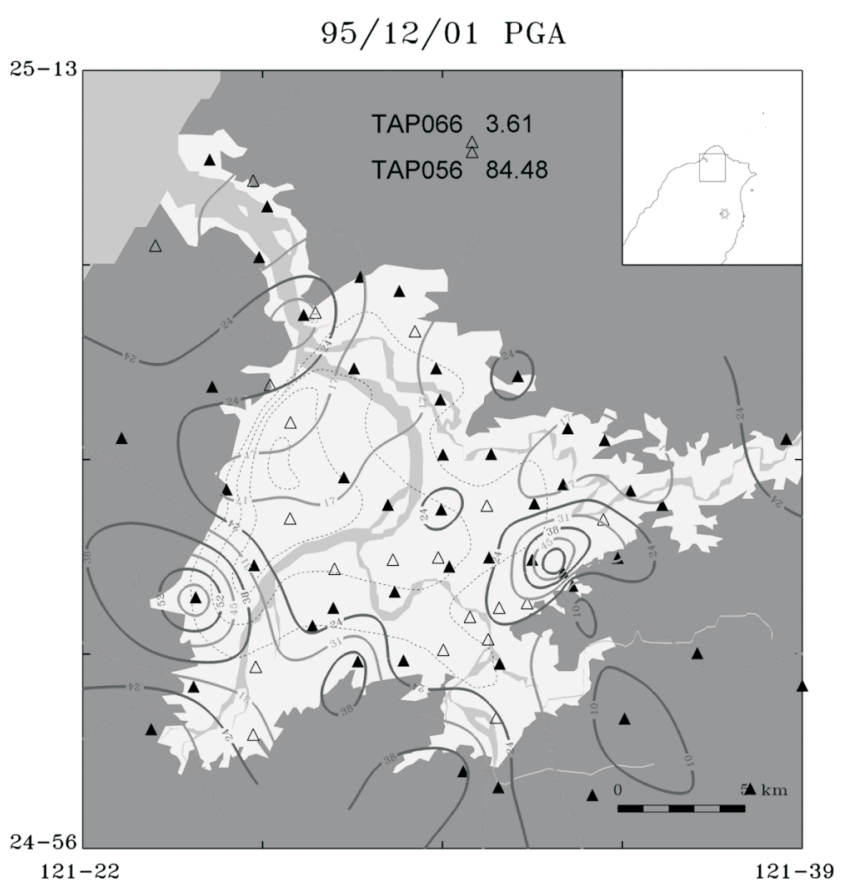

Fig. 4. Horizontal PGA contour for the 1 December 1995 earthquake. Triangles are the strong motion stations and the black triangles are the stations triggered by this event except stations TAP056 and TAP066 marked by their PGA values.

of an earthquake that occurred on 1 December 1995 (Event no. 3); triangles show strong motion stations and solid triangles indicate stations triggered by this event except stations
TAP056 and TAP066 marked by their PGAvalues. Based on PGA contours in the Taipei metropolitan area, the PGA value at TAP066 (3.61 gals) is consistent with the pattern in the whole area. Therefore, the high PGA value at TAP056 station (84.48 gals) seems to be the result of local site effects.

After comparing the PGAratio with focal depth, magnitude, epicentral distance, and hypocentral distance show that it cannot find clear relationships between PGA ratios and these parameters. Perhaps the amount of data is still not enough, or this lack of relationship is due to PGA amplification at the TAP056 site not being related to the source and path effects as noted previously.

\section{FREQUENCY DOMAIN ANALYSIS}

To examine the frequency content of the records at these two stations, the records of 5 events are selected (bold circle symbols in Fig. 2) and time domain waveforms are transferred to the frequency domain. Figure 5 shows the average horizontal Fourier amplitude spectra at the two stations for these 5 events. The amplitude spectra show that the amplitude at Station TAP066 (thin line) is much lower than that at TAP056 (bold line) for the same event; and the ground motion at TAP056 is dominantly $8 \sim 10 \mathrm{~Hz}$ approximately for these events whereas readings at TAP066 differ for different events. The average horizontal spectra are very similar for all events at TAP056, no matter the epicentral distance or how large the magnitude. It shows a clear peak amplitude at around $8 \sim 10 \mathrm{~Hz}$. Although the spectrum observed includes
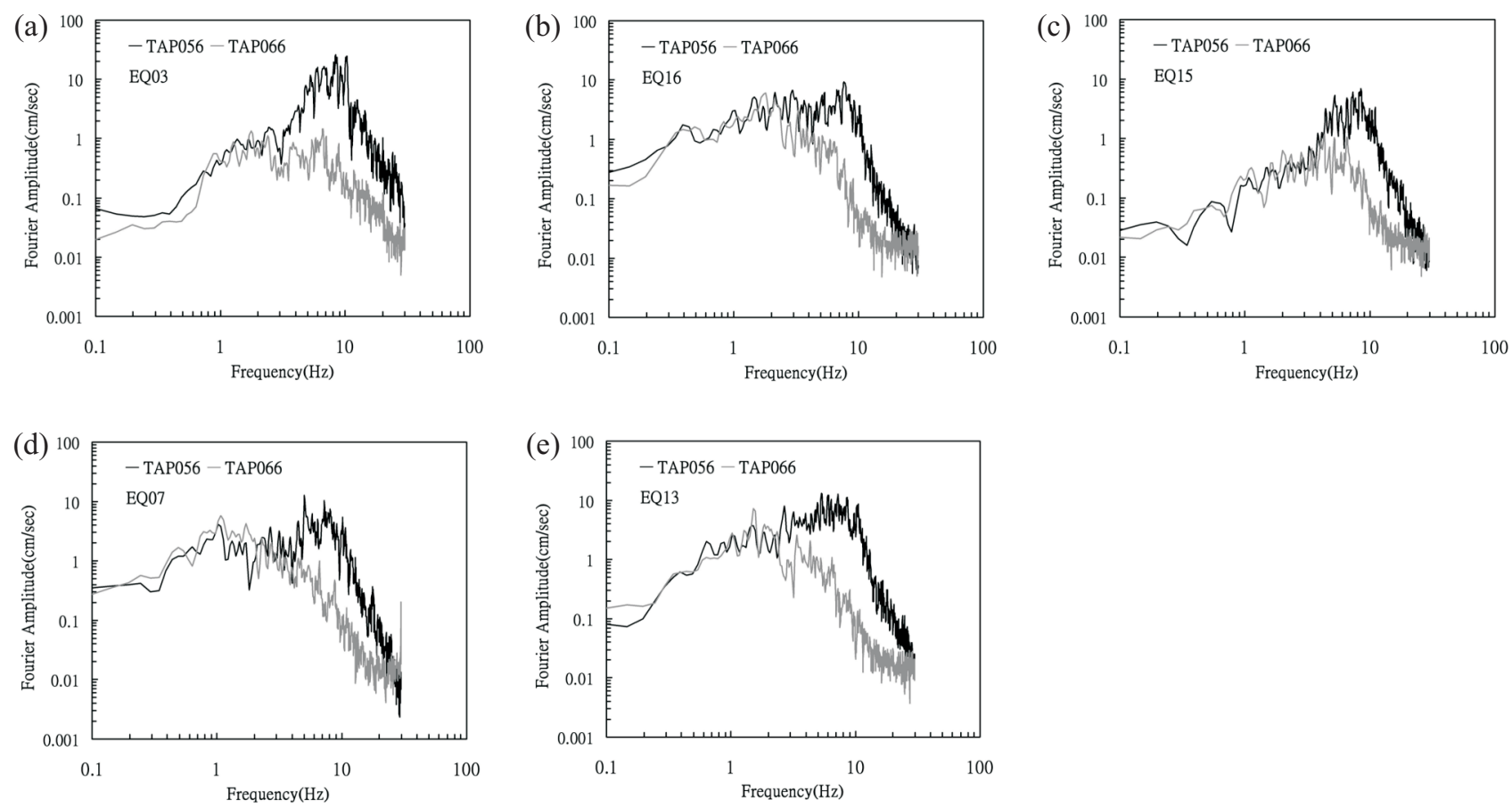

Fig. 5. Average horizontal Fourier amplitude spectra recorded at stations TAP056 and TAP066 of the 5 events marked in Fig. 2. Bold and thin lines are the spectra of TAP056 and TAP066, respectively. 
source, path, and site effects most events are far from the station, and the spectra at TAP066 station do not show this peak. This suggests that the peak at around $8 \sim 10 \mathrm{~Hz}$ might be caused by local site effects at Station TAP056.

To account for the difference at these two stations in the frequency domain, spectral ratios between the two stations are analyzed. Source effects might have had a large influence on the analysis of events no. 1 and 3 with small epicentral distances. Larger epicentral distance will reduce source and path effects. The same spectral ratio method by Beresnev and Wen (1996) is used in this study. The time window is 10 seconds from $\mathrm{S}$ arrival time for the horizontal component. The spectral ratios are plotted in Fig. 6 . The records at TAP056 exhibit significant amplification effect at around $8 \sim 10 \mathrm{~Hz}$ for every event. Ratios in the low frequency section are all around 1, meaning the spectra at TAP056 and TAP066 are around the same in the low frequency band as shown in Fig. 5.

Spectral ratio analysis is a simple yet efficient method for studying site effects. Traditionally, alluvium and rock sites of the two-station spectral ratio method were used to analyze the amplification factor and resonance frequency of an alluvium layer. But, it is not easy to find records at rock sites. Nakamura (1989) proposed a single station spectral ratio method, using microtremor data to study the resonance frequency of a shallow alluvium layer. After that, many studies have used this method to study resonance frequency in different areas. For example, Lermo and ChavezGarcia (1993) applied this method to $\mathrm{S}$ waves, and Field and Jacob (1993) evaluated this single station spectral ratio method through theoretical calculation. Lachet and Bard
(1994) and Dravinski et al. (1996) also showed through theoretical study that the horizontal-to-vertical (H/V) spectral ratio can show the dominant frequency at a site. Wen et al. (2006) used the H/V spectral ratio to identify nonlinear soil response. Figure 7 plots the $\mathrm{H} / \mathrm{V}$ spectral ratio of these events. Figure 7 also shows the dominant frequency at TAP056 station as being in around the $5 \sim 6$ and $8 \sim 10 \mathrm{~Hz}$ frequency bands. The $8 \sim 10 \mathrm{~Hz}$ band is consistent with results from the previous two-station spectral ratiomethod.

As we known, site amplification also relates to input energy. If the input signal did not have energy in the site amplification frequency band, it will not produce any amplified occurrences. So, when considering TAP066 as a rock site, then the signal at TAP066 can be used as an input signal for Station TAP056 for the same event. Figure 8a plots the relationship between PGA ratios and dominant frequencies recorded at TAP066 station for all events. It shows that when the dominant frequency of the input signal is close to the site amplification frequency $(8 \sim 10 \mathrm{~Hz})$ of TAP056, then the PGAratios is larger. Figure $8 \mathrm{~b}$ plots the relationship between the PGAratios and the total energy of the spectra at TAP066 at a frequency band of $8 \sim 10 \mathrm{~Hz}$ (simply integrate the Fourier amplitude spectrum in this frequency band). Figure $8 \mathrm{~b}$ shows that the PGA ratio is larger as input energy in the frequency band of $8 \sim 10 \mathrm{~Hz}$ is bigger. It clearly shows PGA amplification occurring when the input signal has larger energy in the site amplification frequency band.

In summary, for the results of frequency domain analysis, we find that Station TAP056 has a site amplification effect in the frequency band of $8 \sim 10 \mathrm{~Hz}$ when compared to Station TAP066. The cause of this large PGA difference re-
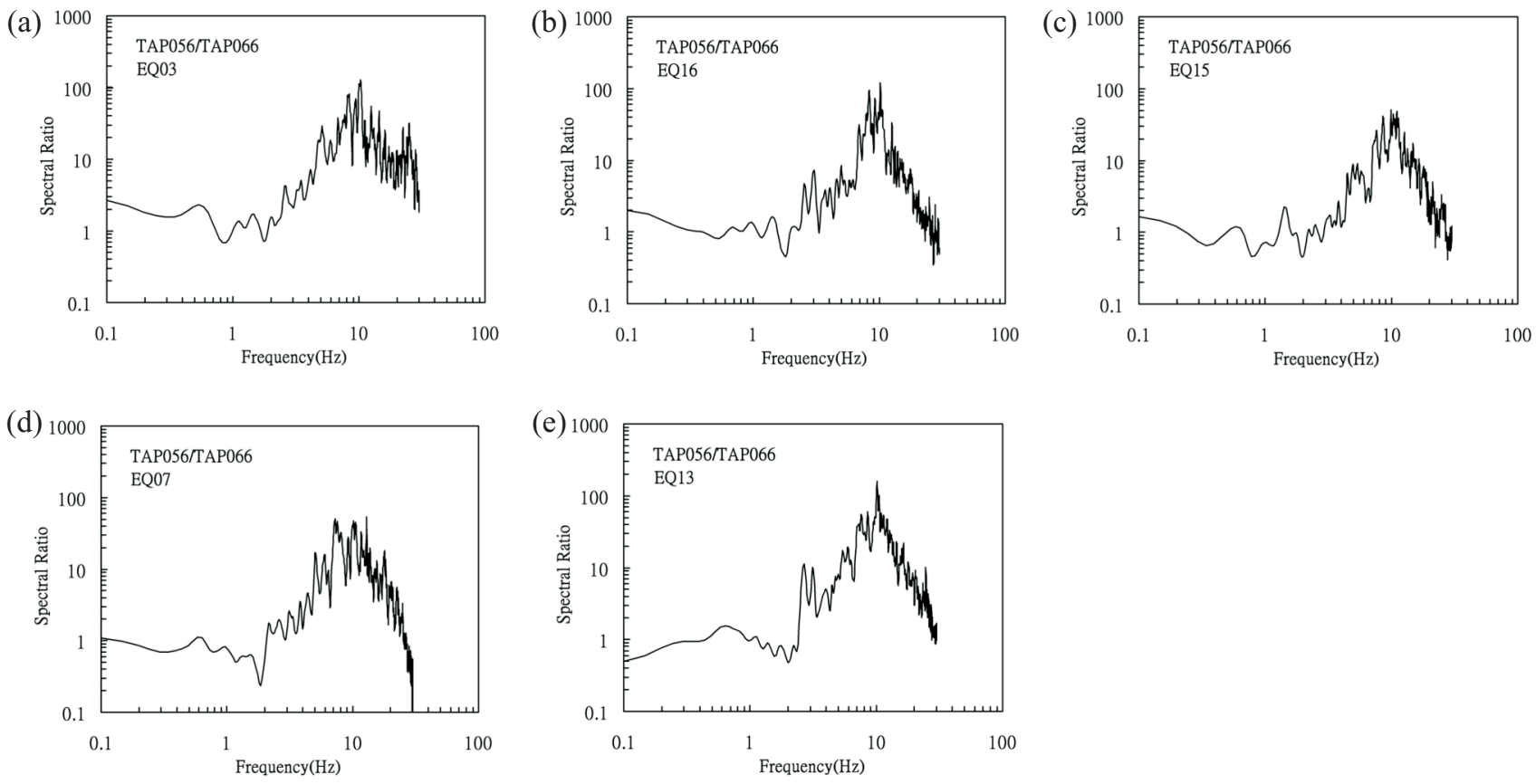

Fig. 6. Spectral ratios between TAP056 and TAP066 for the 5 events shown in Fig. 5 . 

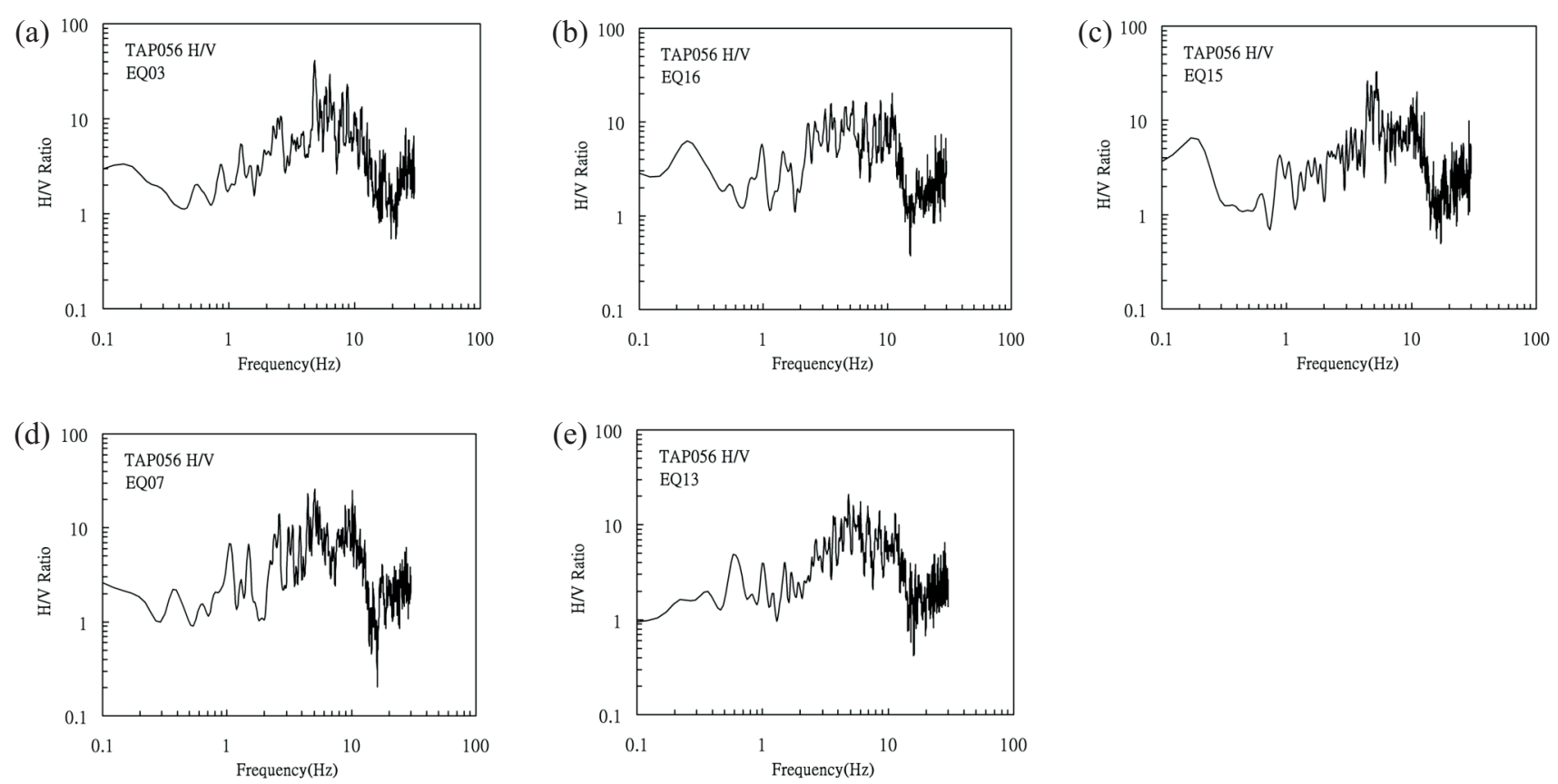

Fig. 7. H/V ratios of the 5 events recorded at Station TAP056.
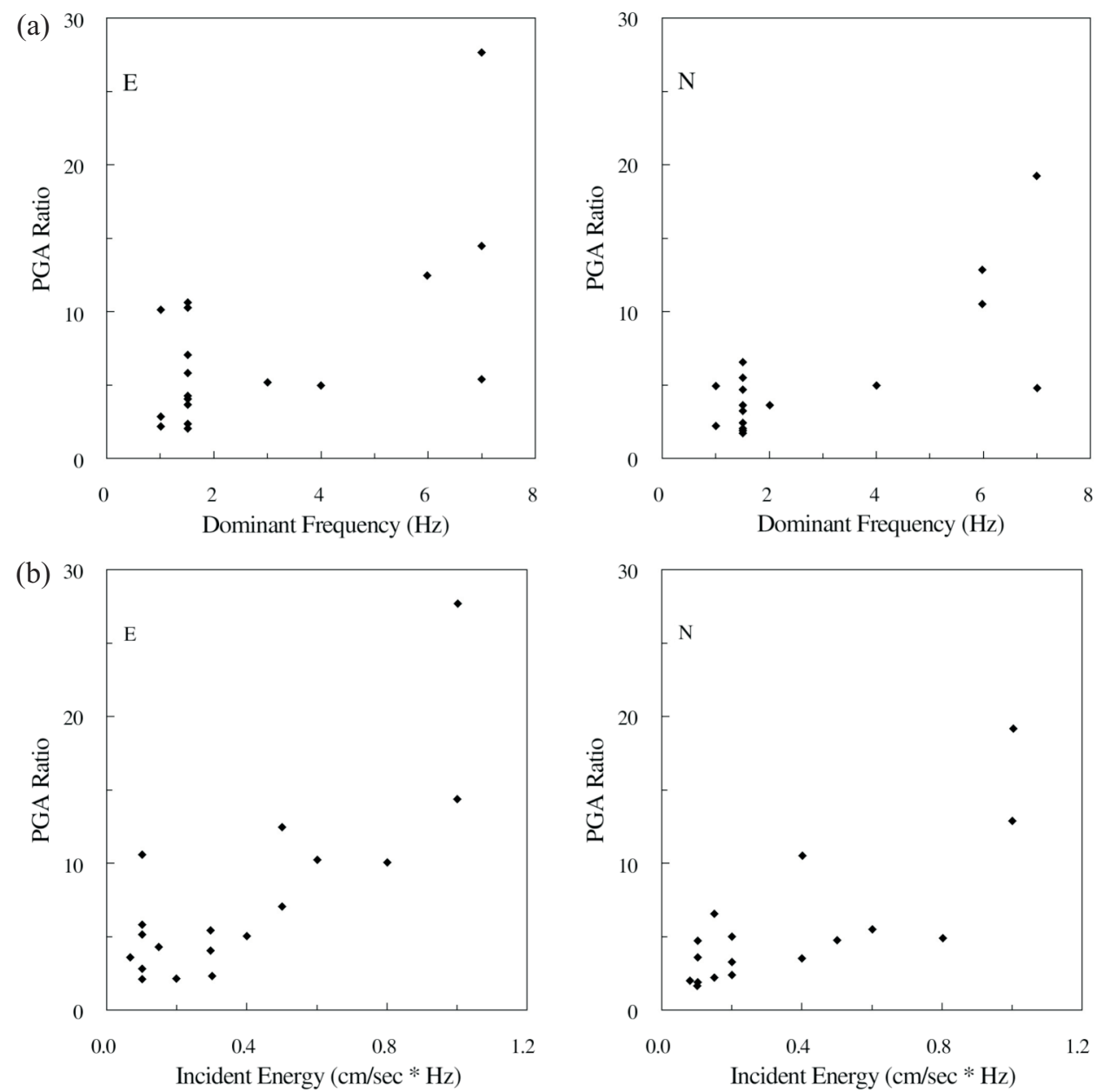

Fig. 8. Relationships between PGA ratios and (a) dominant frequency, and (b) input energy. The energy was calculated using the records of the TAP066 and simply summed for the Fourier amplitude spectrum from 8 to $10 \mathrm{~Hz}$ frequency band. 
corded at these two stations is all attributed to local site effects at the TAP056 station. In terms of site conditions at Station TAP056, it is located in a manmade grassplot on a mountain slope (Fig. 1a). Some in-site investigation methods have been used to determine the reasons for an $8 \sim 10 \mathrm{~Hz}$ site amplification effect at the Station TAP056.

\section{IDENTIFYING THE INFLUENCE OF THE GRASSPLOT}

\subsection{Microtremor Measurements}

Six microtremor survey points (Fig. 9) were selected in

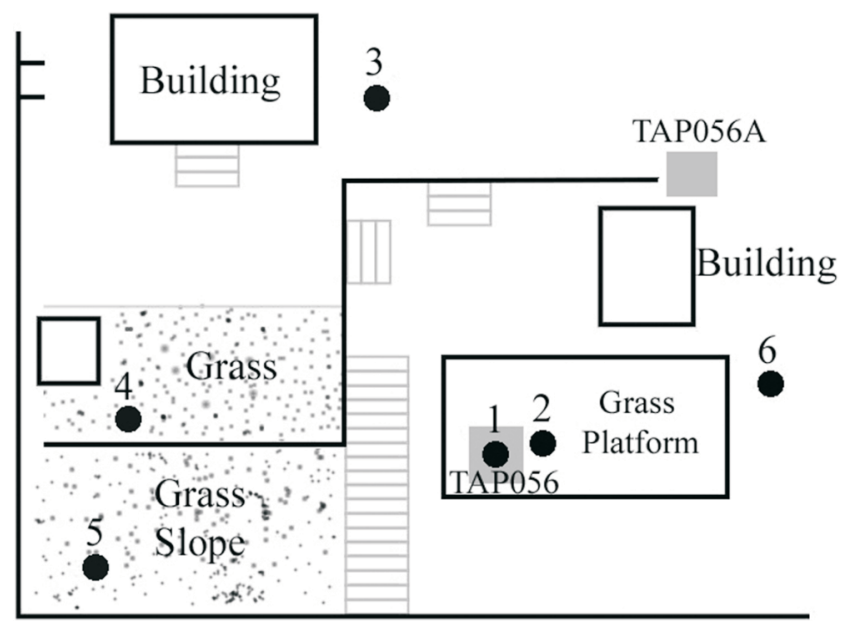

Fig. 9. Sketch for distribution of the microtremor survey points in and near Station TAP056. The detailed map shows in Fig. 1. A temporary station TAP056A is also marked in this figure. the nearby area, including one measuring point near Station TAP056 and 4 outside the grassplot upon which TAP056 is located. The recording time was 18 minutes with a sampling rate of 200 samples per second (sps) at each survey point. The H/V ratios for each survey point are plotted in Fig. 10. All stations have a dominant frequency at around $6 \mathrm{~Hz}$, only measuring-point numbers 1 and 2, which are within the grassplot, had an additional amplification frequency at around $8 \sim 10 \mathrm{~Hz}$. According to the shear wave velocity (about $300 \mathrm{~m} \mathrm{~s}^{-1}$ on average) and thickness (about $12 \mathrm{~m}$ ) for the top weathering layer (Fig. 1b), the resonant frequency is about $6 \mathrm{~Hz}$. This coincides with the results from the H/V spectral ratio shown in Fig. 7 and the microtremor survey results in Fig. 10. It shows that this $8 \sim 10 \mathrm{~Hz}$ amplification frequency is due to the backfilled soft soil of the grassplot where Station TAP056 is located.

To understand site response at the grassplot, 17 dense microtremor measurements were taken in this $16 \times 8 \mathrm{~m}^{2}$ grassplot (Fig. 11). The station interval is about 1 to $3 \mathrm{me}-$ ters. Each measurement has a recording time of 18 mins and a sampling rate of $200 \mathrm{sps}$. All 17 stations have a dominant frequency at around $5 \sim 6 \mathrm{~Hz}$ from the $\mathrm{H} / \mathrm{V}$ spectral ratio. This is the same as that observed outside the grassplot (Fig. 10); however, the H/V ratio from the survey points near the strong motion station TAP056 show a second amplification peak at around $8 \sim 10 \mathrm{~Hz}$. Figure 12 plots some contour maps of the $\mathrm{H} / \mathrm{V}$ ratios at $1,2,5,6,8$, and $10 \mathrm{~Hz}$. It clearly shows that at lower than $5 \sim 6 \mathrm{~Hz}$ the ratios for the whole grassplot are around the same. However, it also clearly shows high amplification near the corner of the grassplot where the TAP056 strong motion station is in the
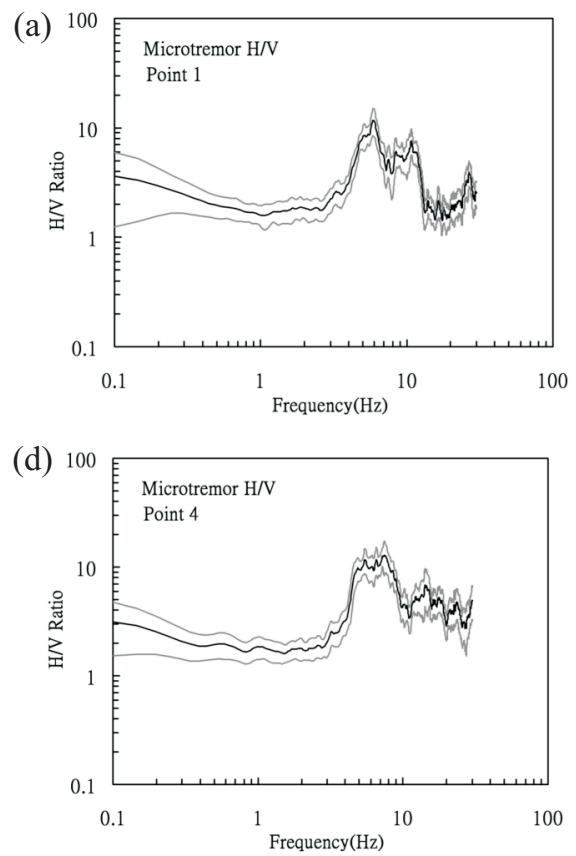
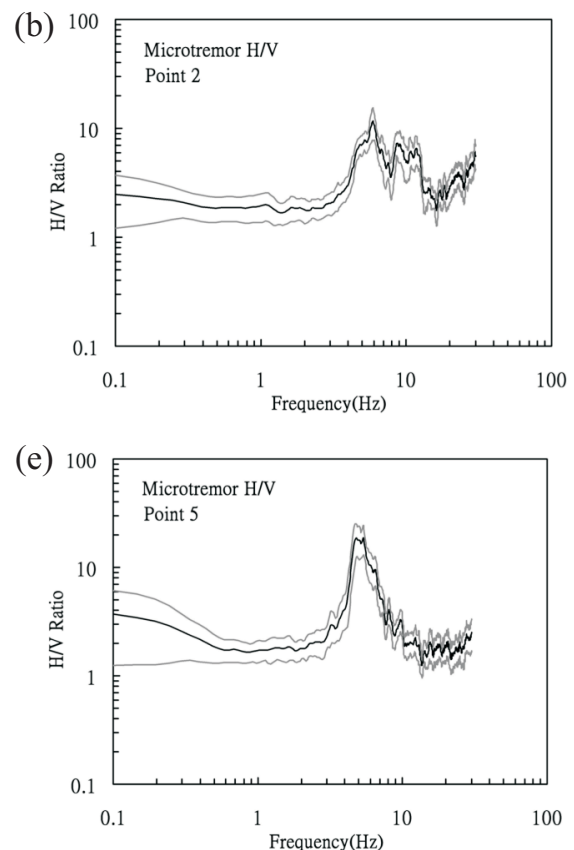
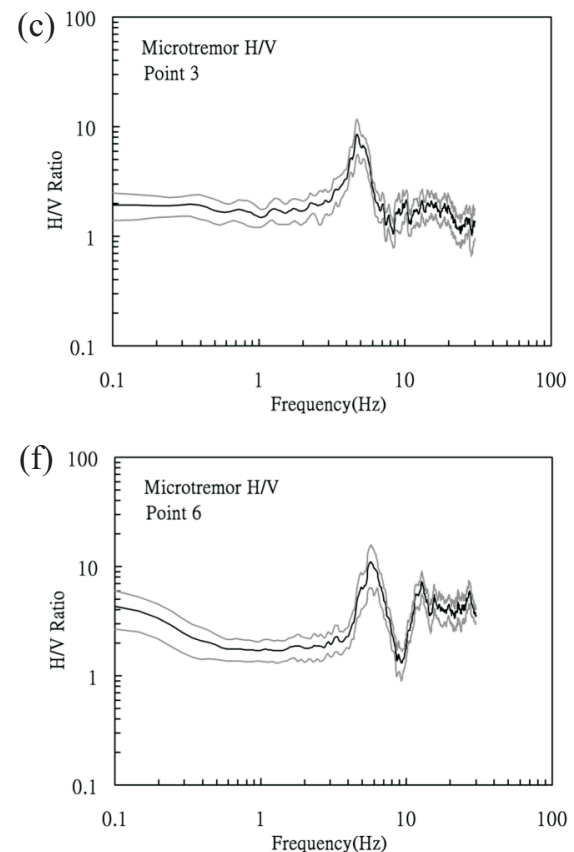

Fig. 10. H/V ratios of the microtremor survey in the TAP056 station area. 


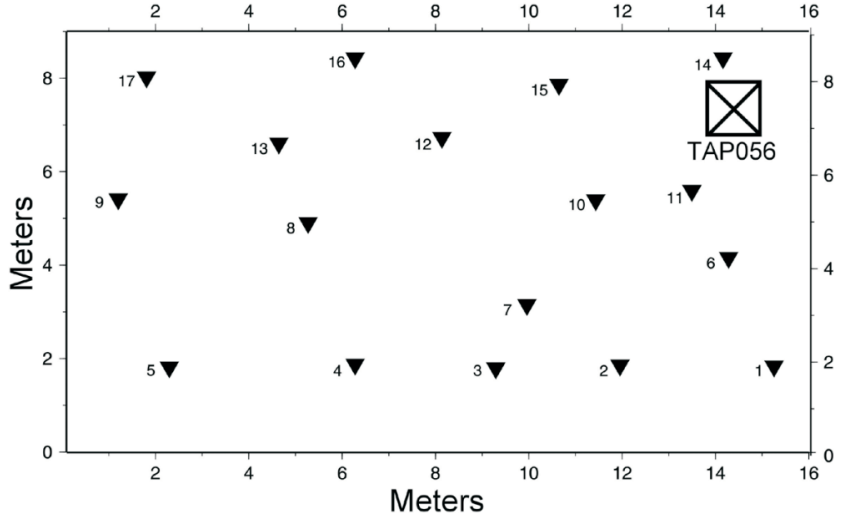

Fig. 11. Densemicrotremor survey points within the grassplot.
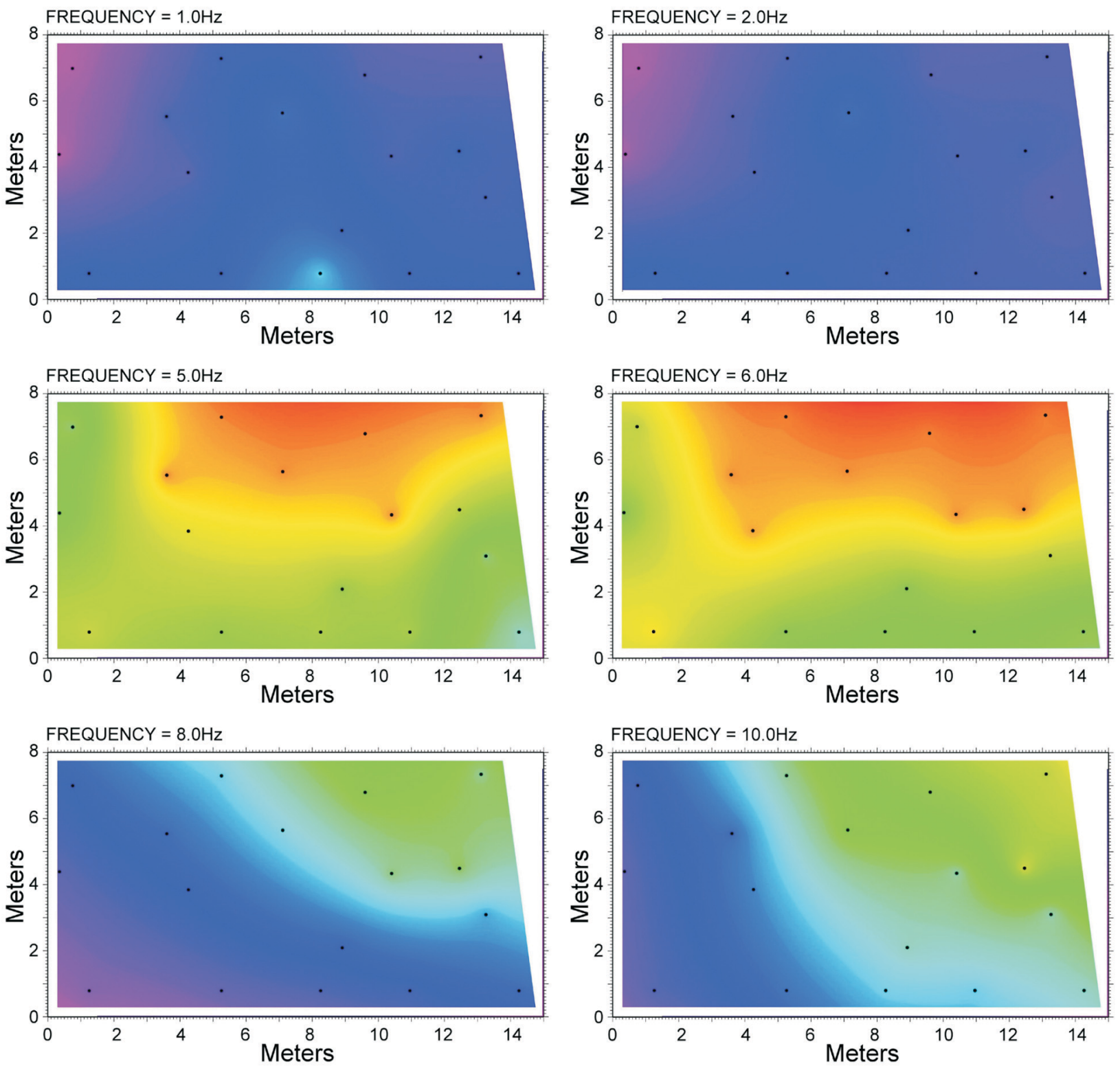

HN Ratio

$8 \sim 10 \mathrm{~Hz}$ frequency band. This indicates that the $8 \sim 10 \mathrm{~Hz}$ site amplification is due to backfilled soft soil and that this feature is only prevalent at the corner where TAP056 is located.

\subsection{Examination by Addition of a Temporary Station}

A temporary strong motion station (referred to as TAP056A) was installed about 20 meters away from TAP056 outside the grassplot (marked in Fig. 9) to prove the influence of the soft grassplot. The same type of instrumentation (ETNA from Kinemetrics, USA) was installed in the TAP056Astation as that in TAP056. Three earthquakes were

Fig. 12. H/V ratios of the dense microtremor survey at 1, 2, 5, 6, 8, and $10 \mathrm{~Hz}$. 
recorded by both stations from 5 January to 12 May 2004 . The epicenters' locations are plotted in Fig. 13 and the source parameters are listed in Table 3.

Figure 14 shows the waveforms of the 11 April 2004 earthquake. The waveforms recorded at these two stations are very normal. But the PGArecorded at Station TAP056 is clearly higher than those at TAP056A by about 4 times. Table 4 listed the PGA of these three events and also the PGA ratios of TAP056/TAP056A. These PGA ratios between the stations inside and outside the grassplot are consistent with the PGA ratios between TAP056 and TAP066 (Table 2). The Fourier spectra and spectral ratio between TAP056 and TAP056A of these three events are plotted in Fig. 15. Again, it shows the site amplification in the dominant frequency band of $8 \sim 10 \mathrm{~Hz}$. All these studies prove site amplification at Station TAP056 is due to the grassplot where TAP056 is located.

\section{RESULTS AND DISCUSSIONS}

Earthquake data recorded at two nearby stations, TAP056 and TAP066, belonging to the TSMIP network are analyzed by two-station and single station methods. Station TAP056 exhibits clear site amplification effects in the frequency band $8 \sim 10 \mathrm{~Hz}$ with respect to the TAP066 rock site. PGA values recorded in the vertical, east-west, and north-

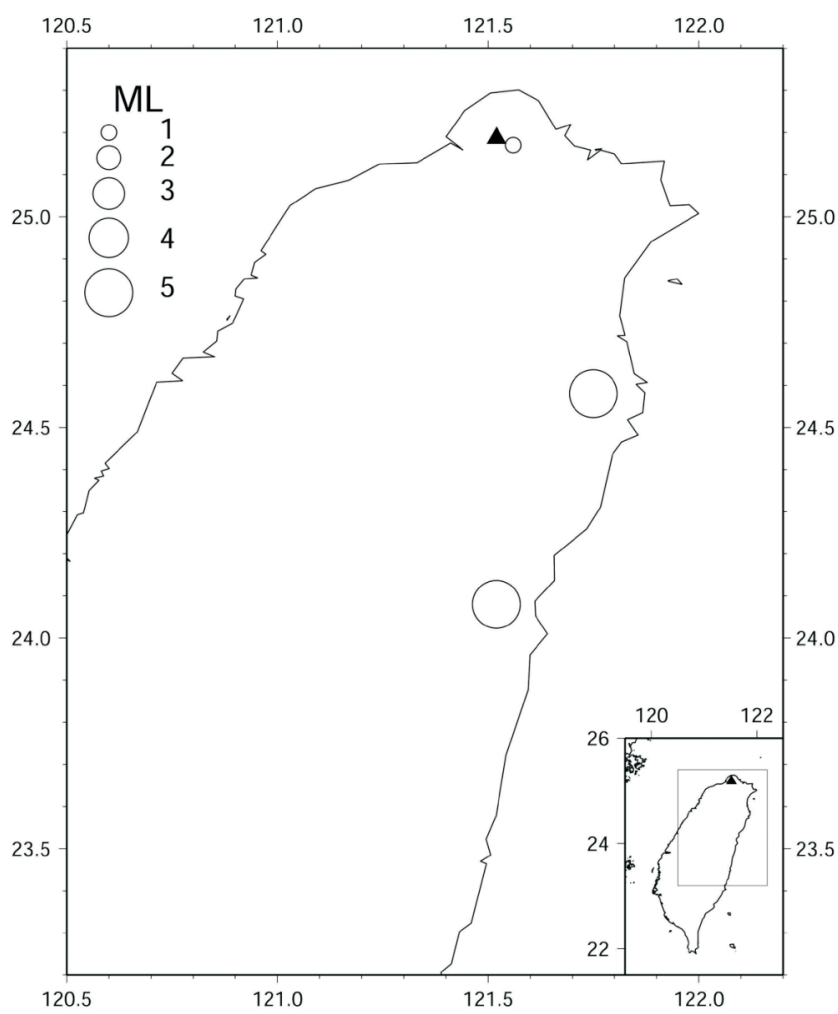

Fig. 13. Epicenter locations for the earthquakes listed in Table 3. The black triangle shows the location of the station. The size of the circle shows the magnitude.

Table 3. Earthquakes recorded by both TAP056 and TAP056A stations.

\begin{tabular}{cccccccc}
\hline \multirow{2}{*}{ Event No. } & \multirow{2}{*}{ Origin Time } & \multicolumn{2}{c}{ Location } & \multirow{2}{*}{ Depth $(\mathbf{k m})$} & \multirow{2}{*}{ Mag. $\mathbf{M}_{\mathbf{L}}$} & $\begin{array}{c}\text { Azimuth }\left({ }^{\circ}\right) \mathbf{T o} \\
\mathbf{T A P 0 6 6}\end{array}$ & $\begin{array}{c}\Delta(\mathbf{k m}) \text { to } \\
\text { TAP066 }\end{array}$ \\
\cline { 3 - 4 } & & ${ }^{\circ} \mathbf{N}$ & ${ }^{\circ} \mathbf{E}$ & & & & \\
\hline 1 & $2004 / 04 / 11$ & 25.17 & 121.56 & 3.2 & 1.5 & 110.12 & 3.22 \\
2 & $2004 / 05 / 01$ & 24.08 & 121.52 & 17.8 & 5.8 & 180.48 & 121.84 \\
3 & $2004 / 05 / 10$ & 24.58 & 121.75 & 67.1 & 5.7 & 161.50 & 70.08 \\
\hline
\end{tabular}
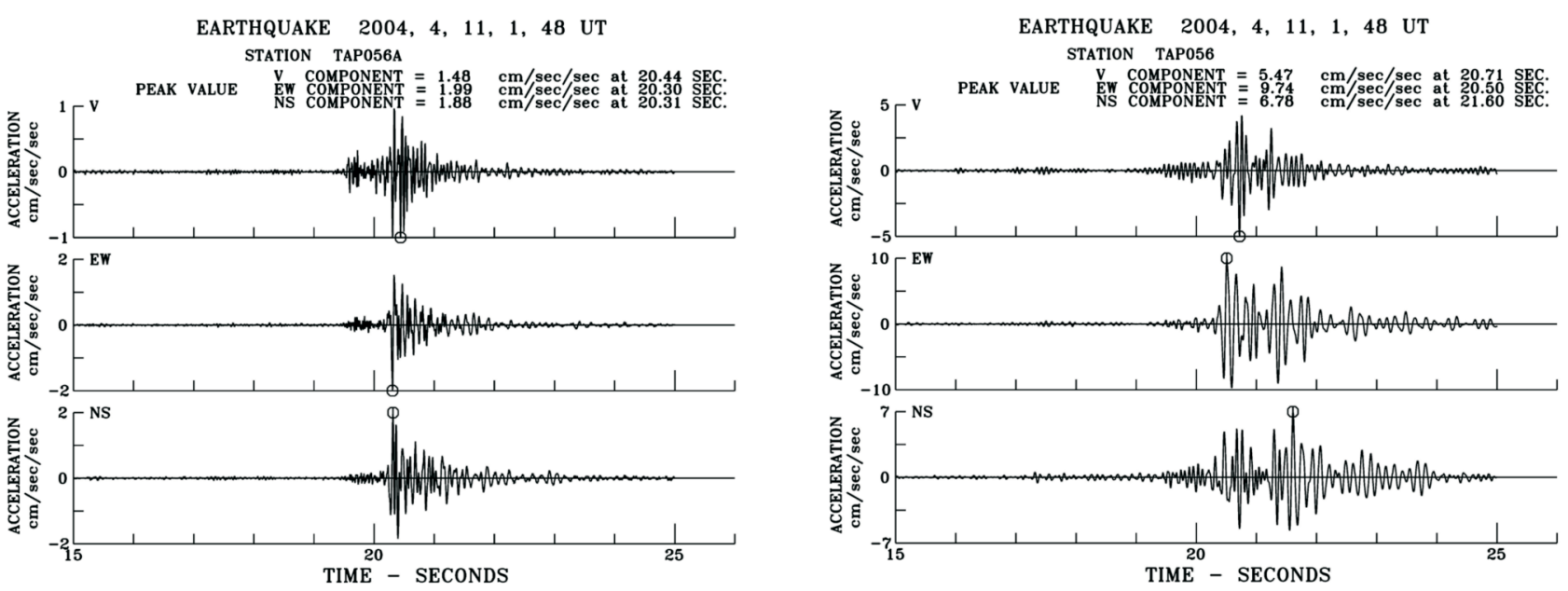

Fig. 14. Acceleration waveforms of the 11 April 2004 earthquake. The waveforms from top to bottom are UD, EW, and NS components for stations TAP056A and TAP056, respectively. 
Table 4. PGA and PGA ratios of stations TAP056 and TAP056A.

\begin{tabular}{|c|c|c|c|c|c|c|c|c|c|}
\hline \multirow{2}{*}{ NO. } & \multicolumn{3}{|c|}{ TAP056 } & \multicolumn{3}{|c|}{ TAP056A } & \multicolumn{3}{|c|}{ TAP056/TAP056A } \\
\hline & EW & NS & V & EW & NS & V & EW & NS & V \\
\hline 1 & 9.74 & 6.78 & 5.47 & 1.99 & 1.88 & 1.48 & 4.89 & 3.61 & 3.70 \\
\hline 2 & 10.41 & 7.65 & 2.17 & 2.68 & 2.75 & 0.92 & 3.88 & 2.78 & 2.36 \\
\hline 3 & 47.32 & 36.41 & 6.50 & 6.86 & 9.86 & 2.94 & 6.90 & 3.69 & 2.21 \\
\hline \multicolumn{7}{|c|}{ Average Ratio } & $5.23 \pm 1.53$ & $3.36 \pm 0.50$ & $2.76 \pm 0.82$ \\
\hline
\end{tabular}

* The unit of PGA is gal.
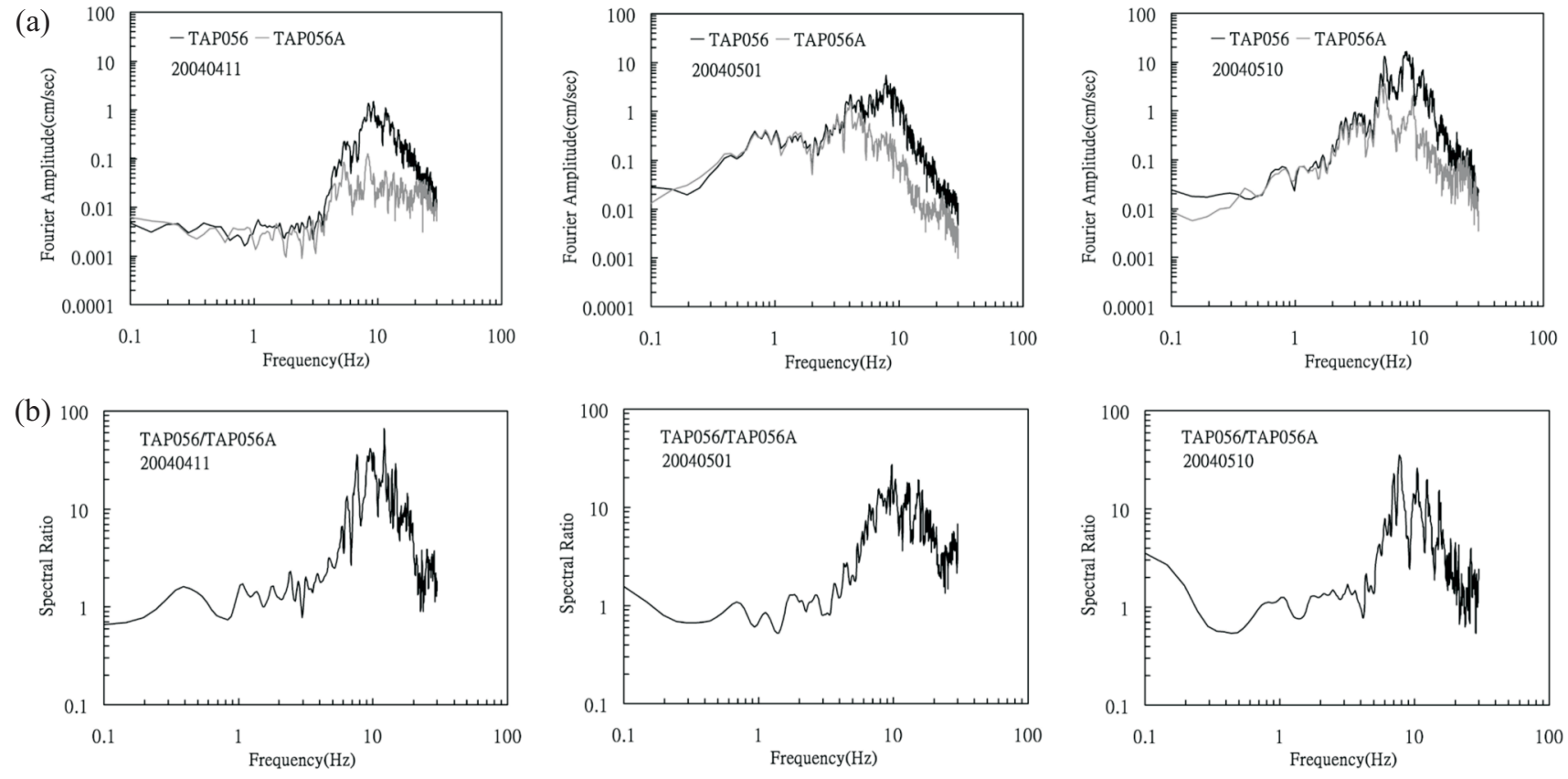

Fig. 15. (a) Fourier spectra and (b) spectral ratios of the three events recorded by stations TAP056 and TAP056A.

south components of TAP056 are 3.89, 7.57, and 5.45 times those at Station TAP066, respectively.

To understand the reasons behind this site amplification effect, a microtremor survey was performed in the surrounding area of the TAP056 site. From this survey, only measurement points within the grassplot, where TAP056 is located, have a dominant frequency at around $8 \sim 10 \mathrm{~Hz}$. After conducting 17 intensive microtremor measurements within the $16 \times 8 \mathrm{~m}^{2}$ grassplot, $\mathrm{H} / \mathrm{V}$ ratios show a dominant frequency band at $5 \sim 6 \mathrm{~Hz}$ for the whole grassplot area. However, measurement points near the corner of the plot where TAP056 is located have a second amplification frequency band of $8 \sim$ $10 \mathrm{~Hz}$. This shows that site amplification effect in earthquake ground motions recorded at Station TAP056 is due to the backfilled soft soil layer used to make the grassplot. The retaining wall of the grassplot is about $2 \mathrm{~m}$ high near Station TAP056. According to the resonant frequency and thickness of the weathering layer, the shear wave velocity is about 64 $80 \mathrm{~m} \mathrm{~s}^{-1}$. This coincides with the description by staff at the
Chutzuhu meteorological observation station that the grassplot is muddy on rainy days. According to shear wave velocity (about $300 \mathrm{~ms}-1$ on average) and thickness (about $12 \mathrm{~m}$ ) of the top weathering layer (Fig. 1b), the resonant frequency is about $6 \mathrm{~Hz}$. This agrees with the results from $\mathrm{H} / \mathrm{V}$ spectral ratios of earthquake recordings shown in Fig. 7 and the microtremor measurements shown in Figs. 10 and 12.

In addition, this research set up a temporary strong motion station (TAP056A) about $20 \mathrm{~m}$ away from Station TAP056 outside the grassplot where TAP056 is installed. Three earthquakes were recorded by both stations within 6 months after the installation of TAP056A. Comparison of recordings in time and frequency domains between TAP056 and TAP056A all show that site amplification effects observed at TAP056 are controlled by the grassplot where Station TAP056 is located. This result emphasizes the point that the effects of surface geology are very important in earthquake ground motion observations. In this case, a thin backfilled soft soil layer had a strong impact on instrument re- 
cordings giving strong site amplification effects to earthquake ground motions. Site effects clearly need to be carefully considered when applying station recordings to seismology studies and engineering projects.

Acknowledgements We would like to thank Dr. C. F. Wu of the CentralWeather Bureau, Taiwan for his help in field work within the TAP056 strong motion station. We also thank two anonymous reviewers for their valuable comments and suggestions. This study was supported by the National Science Council under the grant number NSC932625-Z-008-004 and the Central Weather Bureau under grant number MOTC-CWB-94-E-08.

\section{REFERENCES}

Beresnev, I. A. and K. L. Wen, 1996: The accuracy of soil response estimates using soil-to-rock spectral ratios. Bull. Seismol. Soc. Am., 86, 2, 519-523.

Beresnev, I. A., K. L. Wen, and Y. T. Yeh, 1994: Source, path, and site effects on dominant frequency and spatial variation of strong ground motion recorded by SMART1 and SMART2 arrays in Taiwan. Earthq. Eng. Struct. Dyn., 23, 583-597.

Chen, K. C., 2003: Strong ground motion and damage in the Taipei basin from the Moho reflected seismic waves during the March 31, 2002, Hualien, Taiwan earthquake. Geophys. Res. Lett., 30, doi: 10.1029/2003GL017193.

Chin, B. H. and K. Aki, 1991: Simultaneous study of the source, path, and site effects on strong ground motion during the 1989 Loma Prieta earthquake: Apreliminary result on pervasive nonlinear site effects. Bull. Seismol. Soc. Am., 81, 1859-1884.
Dravinski, M., G. Ding, and K. L.Wen, 1996: Analysis of spectral ratios for estimating ground motion in deep basins. Bull. Seismol. Soc. Am., 86, 3, 646-654.

Field, E. and K. Jacob, 1993: The theoretical response of sedimentary layers to ambient seismic noise. Geophy. Res. Lett., 20, 2925-2928.

Kuo, K. W., T. C. Shin, and K. L. Wen, 1995: Taiwan strong motion instrumentation program (TSMIP) and preliminary analysis of site effects in Taipei basin from strong motion data. In: Cheng, F. Y. and M. S. Sheu (Eds.), Urban Disaster Mitigation: The Role of Engineering and Technology, Elsevier Science Ltd., 47-62.

Lachet, C. and P. Y. Bard, 1994: Numerical and theoretical investigations on the possibilities and limitations of Nakamura's technique. J. Phys. Earth, 42, 377-397.

Lermo, J. and F. J. Chavez-Garcia, 1993: Site effect evaluation using spectral ratios with only one station. Bull. Seismol. Soc. Am., 83, 1574-1594.

Nakamura, Y., 1989: Amethod for dynamic characteristics estimations of subsurface using microtremors on the ground surface. QR RTRI, 30, 25-33.

Shin, T. C., 1993: Progress Summary of the Taiwan Strong Motion Instrumentation Program. Proc. of Symposium on Taiwan Strong Motion Instrumentation Program, 1-10.

Wen, K. L., H. Y. Peng, Y. B. Tsai, and K. C. Chen, 2001: Why $1 \mathrm{~g}$ was recorded at TCU129 site during the 1999 Chi-Chi, Taiwan earthquake? Bull. Seismol. Soc. Am., 91, 12551266.

Wen, K. L., T. M. Chang, C. M. Lin, and H. J. Chiang, 2006: Identification of nonlinear site response using the H/V spectral ratio method. Terr. Atmos. Ocean. Sci., 17, 533-546. 